\title{
Air pollution and children's asthma-related emergency hospital visits in southeastern France
}

\author{
Julie Mazenq ${ }^{1}$ - Jean-Christophe Dubus ${ }^{1}$ - Jean Gaudart ${ }^{2} \cdot$ Denis Charpin $^{3}$. \\ Antoine Nougairede ${ }^{4,5} \cdot$ Gilles Viudes $^{6} \cdot$ Guilhem Noel $^{6,7}$
}

Received: 15 February 2016 / Revised: 18 March 2017 / Accepted: 23 March 2017 /Published online: 5 April 2017

(C) Springer-Verlag Berlin Heidelberg 2017

\begin{abstract}
Children's asthma is multifactorial. Environmental factors like air pollution exposure, meteorological conditions, allergens, and viral infections are strongly implicated. However, place of residence has rarely been investigated in connection with these factors. The primary aim of our study was to measure the impact of particulate matter (PM), assessed close to the children's homes, on asthma-related pediatric emergency hospital visits within the Bouches-du-Rhône area in 2013. In a nested case-control study on 3- to 18-year-old children, each control was randomly matched on the emergency
\end{abstract}

room visit day, regardless of hospital. Each asthmatic child was compared to 15 controls. $\mathrm{PM}_{10}$ and $\mathrm{PM}_{2.5}$, meteorological conditions, pollens, and viral data were linked to ZIP code and analyzed by purpose of emergency visit. A total of 68,897 visits were recorded in children, 1182 concerning asthma. Short-term exposure to $\mathrm{PM}_{10}$ measured near children's homes was associated with excess risk of asthma emergency visits (adjusted odds ratio 1.02 (95\% CI 1.01-1.04; $p=0.02)$ ). Male gender, young age, and temperature were other risk factors. Conversely, wind speed was a protective factor.
Revisions received: 04 Mar 2016 / 19 Mar 2017

Communicated by Peter de Winter

Julie Mazenq

julie.mazenq@ap-hm.fr

Jean-Christophe Dubus

JeanChristophe.Dubus@ap-hm.fr

Jean Gaudart

Jean.Gaudart@ap-hm.fr

Denis Charpin

DenisAndre.Charpin@ap-hm.fr

Antoine Nougairede

Antoine.Nougairede@ap-hm.fr

Gilles Viudes

Contact@orupaca.fr

Guilhem Noel

Guilhem.Noel@ap-hm.fr
1 Pediatric Pulmonology Department, Timone Children's Hospital, 264 rue Saint Pierre, 13005 Marseille, France

2 Aix-Marseille University, UMR912 SESSTIM (AMU-IRD-INSERM), Marseille, France

3 Pulmonology and Allergology Department, Hôpital Nord, Marseille, France

4 IRD French Institute of Research for Development, EHESP, French School of Public Health, EPV UMR D 190 "Emergence des Pathologies Virales", Aix Marseille University, Marseille, France

5 University Mediterranean Hospital Institute for Infections, Marseille, France

6 Regional Emergencies Observatory, Provence-Alpes-Cote d'Azur region (ORU PACA), Hyères, France

7 Pediatric Emergency Department, Hôpital Nord, Marseille, France 
Conclusion: $\mathrm{PM}_{10}$ and certain meteorological conditions near children's homes increased the risk of emergency asthma-related hospital visits in 3- to 18-year-old children in Bouches-du-Rhône.

\section{What is Known: \\ - A relationship between short-term exposure to air pollution and in- crease in emergency room visits or hospital admissions as a result of increased pollution levels has already been demonstrated. \\ What is New: \\ - This study confirms these results but took into account confounding factors (viral data, pollens, and meteorological conditions) and is based on estimated pollution levels assessed close to the children's homes, rather than those recorded at the hospital. \\ - The study area, the Mediterranean, is favorable to creation of secondary pollutants in these sunny and dry seasons.}

Keywords Asthma $\cdot$ Children $\cdot$ Air pollution

$\begin{array}{ll}\text { Abbreviations } \\ \text { BdR } & \text { Bouches-du-Rhône } \\ \text { ED } & \text { Emergency department } \\ \text { EEDA } & \text { Electronic Emergency Department Abstracts } \\ \text { INSEE } & \begin{array}{l}\text { Nation Institute of Statistics and Economic } \\ \text { Surveys }\end{array} \\ & \text { Adjusted odds ratio } \\ \text { ORa } & \text { Emergency Department Observatory of } \\ \text { PACA } & \text { Provence-Alpes-Côte d'Azur region } \\ \text { PM } & \text { Particulate matter } \\ \text { WHO } & \text { World Health Organization }\end{array}$

\section{Introduction}

In both developed and developing countries, outdoor air pollution constitutes a major environmental health concern [30]. Pollutants have a direct irritant and inflammatory effect on neuroreceptors in the airways and bronchial epithelium. Particulate matter (PM) induces airway inflammation and airway hyperresponsiveness (oxidative stress, immunology response, and remodeling). Genetic predisposition and atopy are also important factors [10, 17-19]. In Europe, a significant proportion of the population, especially in cities, still lives in areas where air quality standards set for maximum allowable pollutants are exceeded (ozone, nitrogen dioxide, PM) [2]. The air quality monitoring network AIR PACA (ProvenceAlpes-Côte-d'Azur: south-eastern France) reported a total of 122 days when the daily limit value for PM is exceeded, while the national average is 35 days per year [4]. In the period from 2004 to $2006,19,000$ deaths per year could have been prevented if 25 European cities had met the guide values set by the World Health Organization (WHO) for annual average concentrations of $\mathrm{PM}_{2.5}$. For Marseille, a reduction in life expectancy of 7.5 years was computed [22].

In recent decades, several epidemiological studies reported an association between short-term exposure to air pollution and adverse health effects, showing an increase in emergency room visits or hospital admissions as a result of increased pollution levels $[1,7,8,26,27]$. In a recent review, all 25 included studies reported an association between outdoor air pollution and asthma incidence in children [28]. It has been shown that average rates of pollutants $\left(\mathrm{PM}_{10}\right.$, ozone, nitrogen dioxide, carbon monoxide, and benzene) vary; similarly, rates of nasal eosinophils, values for the fraction of exhaled nitric oxide, and peak flow charts have been found to vary over a week in asthmatic children [23]. However, few epidemiological studies take into account confounding factors such as meteorological conditions, viral infections, and pollen counts according to place of residence $[6,14,27]$. For a decade, no French study has evaluated the impact of pollution on asthmatic disease, despite the lowering of the WHOrecommended threshold values.

The aim of our study was to measure the impact of PM, assessed close to the homes of the children, on asthma-related pediatric hospital visits to the emergency department (ED) within the Bouches-du-Rhône area (BdR) (France) in 2013 and to estimate risks from pollution, meteorological conditions, pollen exposure, and level of respiratory virus circulation.

\section{Methods}

\section{Study area}

The study was conducted in the BdR area of southeastern France $\left(5087 \mathrm{~km}^{2} ; 2.01\right.$ million inhabitants: National Institute of Statistics and Economic Surveys (INSEE 2011)).

Large urban areas, dense road and motorway networks, and industrial zones make it the most important area for air pollutant emissions in the Provence-Alpes-Côte d'Azur region.

\section{Population under study}

Electronic Emergency Department Abstracts (EEDA), mandatory for every patient admitted to an ED in France, are directly available from the patients' computerized medical files. Collected via an ED terminal, EEDAs are anonymously transmitted daily to the French Institute of Public Health Surveillance. EEDAs report date of emergency room visit, age of patient, ZIP code of residence, and final diagnosis (using a national standardized thesaurus based on ICD codes). Since 2008, the ED Observatory of Provence-Alpes-Côte d'Azur region (ORUPACA) has collected these data from 55 EDs in the region (1.5 million ED visits reported in 2013). 
From January 1 to December 31, 2013, EEDAs transmitted by EDs located in BdR were included if they concerned a 3- to 18-year-old child living in BdR. Visits for an exacerbation of asthma were defined according to ICD-10 codes included in the national thesaurus (J45-J46).

Patients' ZIP codes were used to link pollution, pollen, and meteorological data.

The study was approved by "Commission Nationale de l'Informatique et des Libertés" (CNIL), the French data protection authority $\left(\mathrm{n}^{\circ} 1887366\right)$, and by the ethics committee of the French Pediatrics Society (CER_SFP 2015-005).

This study was purely observational and consent of participants was not required because the research involved no intervention or contact with the patient. Only anonymous data were used.

\section{Exposure data}

\section{Air pollution data}

For each ZIP code, daily averages were considered for two primary air pollutants measured in micrograms per cubic meter: $\mathrm{PM}_{10}$ (particulate matter with a diameter less than $10 \mu \mathrm{m}$ ) and $\mathrm{PM}_{2.5}$ (particulate matter with a diameter less than $2.5 \mu \mathrm{m}$ ). These measurements were taken by the air quality monitoring network AIR PACA at 17 stations throughout BdR (including five stations measuring $\mathrm{PM}_{2.5}$ ). For $\mathrm{PM}_{10}$ data, a spatial pollution surface was created. $\mathrm{PM}_{10}$ data were processed via the deterministic CHIMERE chemistry-transport model over a 4-km grid. Then, a communal aggregation mesh was performed, using an average weight by population residing in each mesh.

For $\mathrm{PM}_{2.5}$, each ZIP code was assigned to the nearest "straight line distance" measuring station.

\section{Meteorological data}

For each ZIP code, five daily weather indicators were recorded: average temperature $\left({ }^{\circ} \mathrm{C}\right)$, air humidity $(\%)$, average sea pressure $(\mathrm{hPa})$, average wind speed $(\mathrm{m} / \mathrm{s})$, and rainfall $(\mathrm{mm})$. These data were obtained from the monitoring network Météo-France and taken from a total of 151 monitoring stations. Each ZIP code was assigned to the nearest "as the crow flies" measuring station.

\section{Pollen data}

For each ZIP code, the main taxa of BdR (cypress, birch, ash, grass pollen, and urticaceae) were collected from two stationary pollen traps in BdR by the national network for aerobiological monitoring. The maximum distance between $\mathrm{BdR}$ communes and measuring stations was roughly $100 \mathrm{~km}$ (roof of Hospital Nord and roof of Hospital of Aix-en-Provence). Each BdR ZIP code was linked to the nearest monitoring station.

\section{Virological data}

For each day in 2013, the daily level of respiratory virus circulation was defined by the total number of positive specimens (nasopharyngeal swabs or aspirates) found in the Virology laboratory of the public hospitals of Marseille for each of the following viruses: respiratory syncytial virus, rhinoviruses, influenza A virus, influenza B virus, and human metapneumovirus. The daily level of respiratory virus circulation was used as a proxy of daily viral exposure in BdR.

\section{Other data not available}

On Electronic Emergency Department Abstracts, no information about smoke exposure, familial asthma, atopy, and/or prematurity were available.

\section{Statistical analysis}

First, variables were selected using principal component analysis (for each continuous variable). Each control was randomly matched on the emergency room visit day, regardless of hospital. Then, the nested case-control design used univariate analyses to select variables $(p<0.20)$ via conditional logistic regressions and to assess interactions between covariates. Multivariate analysis was performed with a stepwise procedure using conditional logistic regression, to accurately estimate the odds ratio (OR). Each asthmatic child was compared to 15 controls, to improve the quality and analytical power. The impact of pollution, weather, pollen, and virus risk on asthma-related emergency room visits was assessed by taking day 0 to the exposure (i.e., the same day: air pollution exposition and visits to emergency department) and evaluated interactions pollution and asthma attacks at day 0 and average pollution over the previous 2 to 7 days, by taking average for each day into logistic regression model. For each factor, ORs were estimated depending on their relationship to asthma attacks. Interactions between meteorological factors and pollution or pollen data were also taken into account. A $p$ value of less than 0.05 was considered significant.

Statistical analyses were performed using R3.1.3 software ((C) 2015 The R Foundation for Statistical Computing, Vienna, Austria).

\section{Results}

Of the 17 EDs in the Bouches-du-Rhône, 12 participated in the study via their EEDAs. A total of 68,897 visits recorded for children aged from 3 to 18 years showed that 1182 concerned asthma (1.7\% of total visits). Figure 1 shows the monthly frequency of visits due to asthma during the study period. Figure 2 shows the monthly variation in PM over the period. Table 1 
Fig. 1 Frequency of asthmarelated visits $(n=1182)$ by children aged 3 years to 18 years to emergency departments (ED) during the study period and \% emergency visits for asthma out of total visits $(n=68,897)$ (red line). Bouches-du-Rhône, 2013

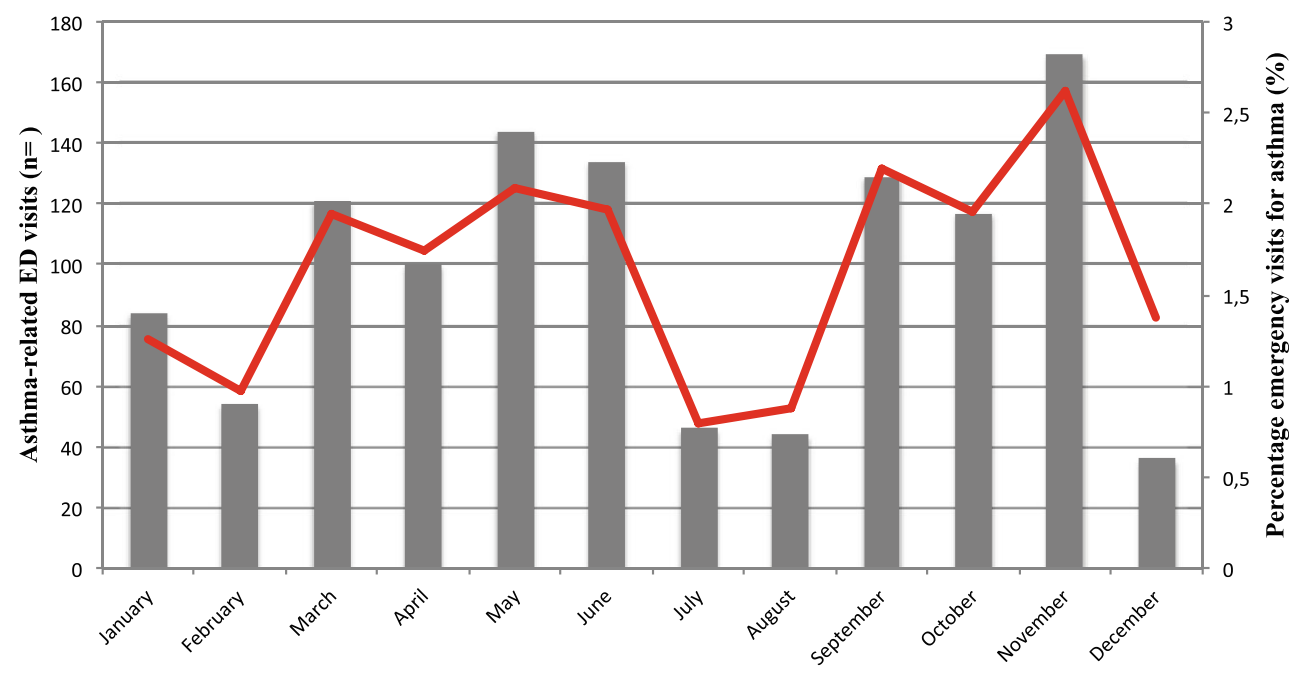

describes the study population with children visiting for asthma attacks and controls.

The impact of pollution on asthma visit was assessed on 1182 cases matched to 18,903 controls.

Quantitative variables selected by principal component analysis for meteorological data were rainfall, temperature, and wind speed; for pollen data, variables were grass pollenurticaceae paired, birch-ash paired and cypress; for respiratory virus circulation, variables were rhinovirus and total virus.

\section{Clinical data}

Males were at higher risk of asthma-related ED visits with an adjusted OR (ORa) of 1.14 (95\% CI 1.01-1.28; $p=0.04$ ). Older children had a lower risk of asthma-related visits ORa of 0.89 (95\% CI $0.88-0.90 ; p<0.001$ ) (Table 2).

\section{Impact of PM}

In multivariate analysis, average daily $\mathrm{PM}_{10}$ were a statistically significant risk factor for asthma-related $\mathrm{ED}$ visits in $\mathrm{BdR}$ with ORa $1.02(95 \%$ CI $1.01-1.04 ; p=0.02)$ (Table 2). However, $\mathrm{PM}_{2.5}$ were not found to be a risk factor for asthma attacks (ORa $1.00 ; 95 \%$ CI $0.99-1.02 ; p=0.52$ ). These results were exactly the same when considering the average pollution over the previous 2 to 7 days for both for $\mathrm{PM}_{10}$ and $\mathrm{PM}_{2,5}$.

\section{Impact of meteorological data}

In multivariate analysis, wind speed was a protective factor for asthma, with ORa 0.90 (95\% CI 0.87-0.94; $p<0.001$ ) (Table 2), whereas temperature was statistically linked to asthma attack risk, with ORa 1.09 (95\% CI $1.01-1.17 ; p=0.02$ ). A trend toward increased risk of
Fig. 2 Temporal evolution of pollutants $\left(\mathrm{PM}_{2.5}\right.$ and $\left.\mathrm{PM}_{10}\right)$ during the study period (daily average measured in $\mu \mathrm{g} / \mathrm{m}^{3}$ ). Bouches-du-Rhône, 2013

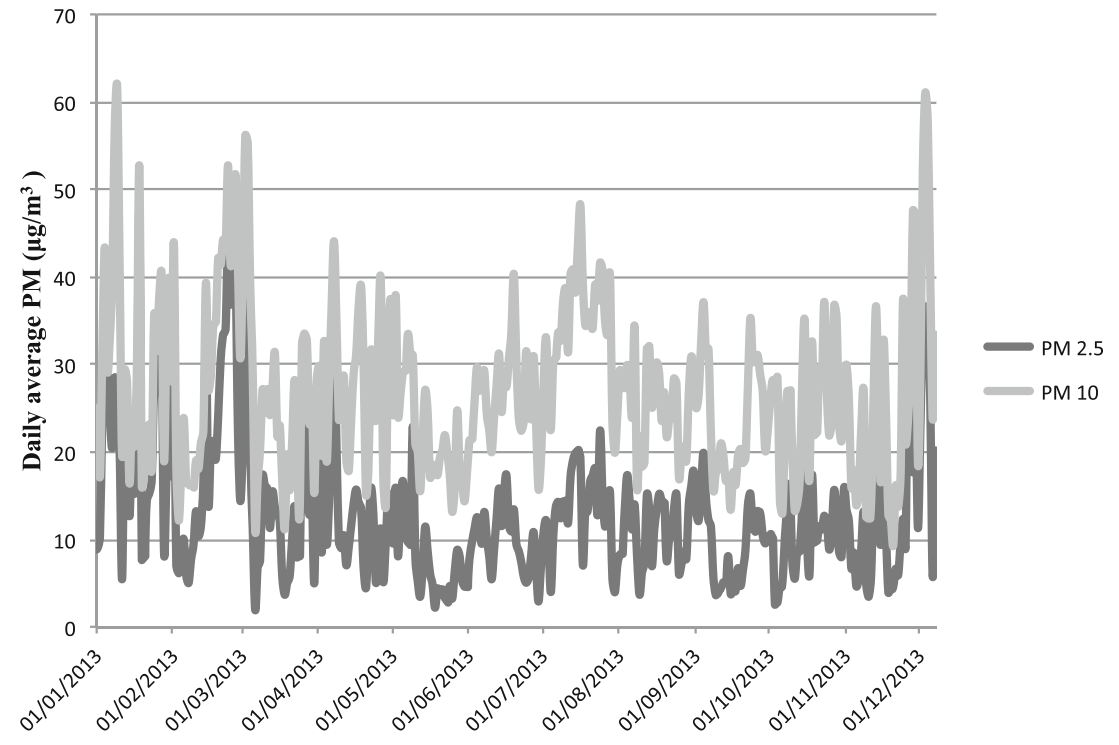


Table 1 Description study population for asthma-related emergency room visits and controls to emergency departments in Bouches-duRhône ( $n=1182$ cases versus 18,903 controls)

\begin{tabular}{llll}
\hline & $\begin{array}{l}\text { Asthma } \\
(n=1182)\end{array}$ & $\begin{array}{l}\text { Controls } \\
(n=18,904)\end{array}$ & $p$ \\
\hline Age (median) (years) & 7.7 & 9.9 & $<0.001^{*}$ \\
Male sex (\%) & 55 & 59 & $0.004^{*}$ \\
\hline
\end{tabular}

$* p<0.005$

asthma was found for rainfall (ORa 1.03; 95\% CI 1.00 1.06; $p=0.07$ ) (Table 2). Interactions between wind speed and PM were not significant.

\section{Impact of pollen data}

In univariate analysis, birch-ash paired was statistically linked to asthma-related ED visits (ORa 0.99; 95\% CI 0.98-0.99; $p=0.03$ ). In multivariate analysis, exposure to different taxa was not a risk factor for asthma-related ED visits. Interactions between wind speed and the different taxonomic groups were not statistically significant.

\section{Impact of level of respiratory virus circulation}

No association with the risk of asthma-related ED visits was found.

Table 2 Multivariate analysis, by conditional logistic regression, in a case-control nested in a cohort, of different selected variables on asthmarelated emergency room visits to emergency departments in Bouches-duRhône ( $n=1182$ cases versus 18,903 controls)

\begin{tabular}{llll}
\hline Variables & ORa & $(95 \%)$ CI & $p$ \\
\hline Gender & 1.14 & $1.01-1.28$ & 0.04 \\
Age $($ years $)$ & 0.89 & $0.88-0.90$ & $<0.001$ \\
$\mathrm{PM}_{10}\left(\mu \mathrm{g} / \mathrm{m}^{3}\right)$ & 1.02 & $1.01-1.04$ & 0.02 \\
$\mathrm{PM}_{2.5}\left(\mu \mathrm{g} / \mathrm{m}^{3}\right)$ & 1.00 & $0.99-1.02$ & 0.52 \\
Rainfall $(\mathrm{mm})$ & 1.03 & $1.00-1.06$ & 0.07 \\
Temperature $\left({ }^{\circ} \mathrm{C}\right)$ & 1.09 & $1.01-1.17$ & 0.02 \\
Wind speed $(\mathrm{m} / \mathrm{s})$ & 0.90 & $0.87-0.94$ & $<0.001$ \\
Cypress $\left(\right.$ grains $\left./ \mathrm{m}^{3}\right)$ & 0.99 & $0.99-1.00$ & 0.33 \\
Urticaceae and grass pollen $\left(\right.$ grains $\left./ \mathrm{m}^{3}\right)$ & 0.99 & $0.99-1.01$ & 0.66 \\
Ash and birch $\left(\right.$ grains $\left./ \mathrm{m}^{3}\right)$ & 0.99 & $0.99-1.00$ & 0.27 \\
Rhinoviruses & NA & NA & NA \\
Total virus & NA & NA & NA \\
\hline
\end{tabular}

Only quantitative variables selected using principal component analysis are represented

$O R a$ adjusted $\mathrm{OR}, N A$ non-applicable

\section{Discussion}

Our study shows a statistically significant association between short-term exposure, from the day of the ED visit up to 1 week before the ED visit, to $\mathrm{PM}_{10}$ measured near children's homes and asthma-related ED visits in 3- to 18-year-old children in the Bouches-du-Rhône area in 2013. Exposure to $\mathrm{PM}_{10}$ increases the risk of an asthma-related ED visit by $2 \%$. The study, which took into account viral data, pollens and meteorological conditions, also identifies other risk factors: male gender, young age, and higher temperature. Conversely, in this study, higher wind speed is a protective factor for asthma.

Our study has some limitations. Ideally, performing direct personal measurements of exposure would provide a more reliable assessment of the effects of pollutants on asthma symptoms or asthma attacks. Continuous measurement of personal exposure to air pollutants is the gold standard for exposure assessment. However, it is impractical and very costly to measure exposure in the large number of participants necessary to satisfy statistical power requirements [16]. Our assessment of PM exposure levels is thus based on a collective measurement of pollution from stationary positions. While we cannot rule out coding errors on the ED software, asthma has an easily recognizable clinical presentation, so the potential for errors was low on this cohort. Moreover, any coding errors would not be linked to pollution levels. Five EDs did not transmit medical data because they were not equipped with the ED software. The relative gravity of asthma exacerbations was not taken into account, because we compiled diagnostic codes "asthma" and "status asthmaticus" according to only one criterion. Moreover, information on other confounding factors such as tobacco smoke exposure or atopy were impossible to evaluate due to our mode of data collection.

Our study is original in that it evaluates children's exposure to PM based on their home ZIP code. Indeed, many other studies look at exposure levels at the receiving ED hospital. Our assessment is more accurate because, according to INSEE, the average home-school distance in Provence-Alpes-Côte-d'Azur is less than $9 \mathrm{~km}$ [13]. Moreover, children are more susceptible than adults to the effects of air pollution because of environmental, behavioral, and physiological factors [18]. Children breathe at a faster rate than adults and spend more time outside engaged in physical activity, so they are exposed to larger doses of ambient air pollution [24].

Despite differences in methods of assessing the $\mathrm{PM}_{10}$ rate, our results are consistent with those reported in the literature. The epidemiological study Air Monitoring and Health Programme (PSAS-9) phase II on nine cities in France found a 0 to $1.7 \%$ excess risk, statistically significant for all respiratory diseases, of hospital admissions related to $\mathrm{PM}_{10}$ exposure level. In this study, $\mathrm{PM}_{10}$ data were missing for six towns and 
asthma-related morbidity was not studied [20]. The APHEA 2 study examined hospital morbidity from 1989 to 1996 in eight European cities, including Paris: a statistically significant link was found between increased $\mathrm{PM}_{10}$ values and hospital admissions for asthma. An increase of $10 \mu \mathrm{g} / \mathrm{m}^{3}$ in $\mathrm{PM}_{10}$ was associated with a $1.2 \%$ increased risk of hospitalization for asthma (95\% CI $0.2-2.3$ ) before the age of 14 and $1.1 \%$ (95\% CI 0.3-1.8) between the ages of 15 and 64. However, this study did not take into account factors such as pollen density or the "circulating viral load," except for the influenza epidemic period. Furthermore, it covered only Paris, which does not have the same demographic characteristics as the Bouches-du-Rhône area [3]. Samoli et al. studied 3601 asthma-related admissions in 0- to 14-year-old children and found a $2.54 \%$ increase mainly in winter and on days of exposure to $\mathrm{PM}_{10}$, with a higher risk of admissions for children aged between 5 and 14 [25]. Sun's study also found a positive correlation between children's asthma-related ED visits and exposure to $\mathrm{PM}_{10}$ [26]. To note, $\mathrm{PM}_{10}$, but also ozone and nitrogen dioxide, are also found associated with pulmonary exacerbation in other respiratory disease: cystic fibrosis [15].

When considering lags of exposure up to 7 days and asthma-related ED visits, we find the same results than at day 0 exposure. Several studies evaluated lags of exposure for pollutants. Samoli et al. analyzed exposure periods (lag $0,1,2)$ and cumulative exposure for 3 days (lag $0-2$ ) and asthma admissions for 0 to 14 years. For $\mathrm{PM}_{10}$, the highest effect was observed on the same day as the admission but significant result was found for all lags [25].

We did not find a statistically significant correlation between $\mathrm{PM}_{2.5}$ level and asthma-related emergency room visits. Contradictory data are found in the literature, probably due to the fact that $\mathrm{PM}_{2.5}$ levels are linked to other pollutants through a cocktail effect [11]. In addition, exposure to $\mathrm{PM}_{2.5}$ was here evaluated at day 0 and in the previous week at five sites; however, such exposure has been found to be a risk factor for asthma-related ED visits up to 5 days before the medical consultation $[12,14,17,29]$. Numerous other factors may also affect assessment of the $\mathrm{PM}_{2.5}$ effect on asthma, especially when exposure measurements are aggregated.

Regarding meteorological factors, Tosca's study found a positive association between emergency calls for asthma exacerbation in children, wind speed, and amount of rainfall [27]. In our study, ambient temperature was a risk factor for asthma-related emergency room visits. Wind speed was a protective factor, perhaps by dispersing pollutants. In contrast, our results did not confirm the influence of rainfall, with a trend to a statistically nonsignificant increase in emergency room visits.

Our study differs from the literature in not finding a link between pollen exposure and asthma-related emergency room visits. This may be related to the fact that we had only two pollen-monitoring stations, and that the maximum distance between the BdR municipalities and the measuring stations was roughly $100 \mathrm{~km}$. This meant that exposure levels for cases and controls were similar. In other studies, emergency calls for asthma exacerbation were significantly correlated with pollen exposure between April and August [27].

We did not find a link with the level of respiratory virus circulation. Bonnelyke et al. in their study of 313 children showed a relationship between asthma attacks and number of respiratory infections, not the virus itself [5]. Similarly, Lee's study found no difference in the detection of viruses among children aged 6 to 14 with asthma exacerbation and those with non-asthma respiratory illness [21]. But our result could also be due to the nested case-control design, as cases and controls showed similar exposure. The present study used data from the Electronic Emergency Department Abstracts mandatory in France and used by the French Institute of Public Health Surveillance for syndromic surveillance, including for asthma [9]. This method could be replicated on a national level, allowing a more accurate evaluation of the effect of viral diseases on asthma-related ED visits.

\section{Conclusion}

Our study shows that short-term local exposure to $\mathrm{PM}_{10}$, assessed close to the homes of the children, is responsible for an increased risk of emergency department visits for asthma exacerbation in 3- to 18-year-old children in the Bouchesdu-Rhône. These findings require further confirmation from other studies on larger cohorts. Such confirmation would suggest that reinforced preventive or therapeutic strategies should be implemented for children with asthma when air pollution levels exceed the regulatory thresholds for $\mathrm{PM}_{10}$.

Acknowledgements We thank Mr. Robin Dominique and his staff at the air quality monitoring network (AirPACA) for collecting the pollution data.

Authors' contribution Julie Mazenq: She conceptualized and designed the study, coordinated and supervised data collection, and drafted the initial manuscript.

Jean-Christophe Dubus: Pr Dubus conceptualized and designed the study and reviewed and revised the manuscript.

Jean Gaudart: Dr. Gaudart carried out the statistics analyses, critically reviewed the manuscript.

Denis Charpin: Pr Charpin designed the pollen data collection instruments and critically reviewed the manuscript.

Antoine Nougairede: Dr. Nougairede designed the virology data collection instruments and critically reviewed the manuscript.

Gilles Viudes: Dr. Viudes is the promoter of the study. He conceptualized and designed the study, critically reviewed the manuscript.

Guilhem Noel: Dr. Noel conceptualized and designed the study, coordinated and supervised data collection, and reviewed and revised the manuscript. 
All the authors approved the final manuscript as submitted and agree to be accountable for all aspects of the work.

\section{Compliance with ethical standards}

Funding source No funding was secured for this study.

Financial disclosure The authors have no financial relationships relevant to this article to disclose.

Conflict of interest The authors declare that they have no conflict of interest.

\section{References}

1. Abe T, Tokuda Y, Ohde S, Ishimatsu S, Nakamura T, Birrer RB (2009) The relationship of short-term air pollution and weather to ED visits for asthma in Japan. Am J Emerg Med 27:153-159

2. Air pollution-European Environment Agency (AEE) 2016. Available online: http://www.eea.europa.eu/themes/air. Accessed 201622 Dec

3. Atkinson RW, Ross Anderson H, Sunyer J, Ayres J, Baccini M, Vonk JM, Boumghar A, Forastiere F, Forsberg B, Touloumi G et al (2001) Acute effects of particulate air pollution on respiratory admissions: results from APHEA 2 project. Air pollution and health: a European approach. Am J Respir Crit Care Med 164: 1860-1866

4. Bilan PM2013 BR.pdf - 130000 Bilan PM2013 BR.pdf 2016. Available online: http://atmopaca.org/files/ba/130000_Bilan_ PM2013_BR.pdf. Accessed 201622 Dec

5. Bønnelykke K, Vissing NH, Sevelsted A, Johnston SL, Bisgaard H (2015) Association between respiratory infections in early life and later asthma is independent of virus type. J Allergy Clin Immunol 136:81-86.e4

6. Cadelis G, Tourres R, Molinie J (2014) Short-term effects of the particulate pollutants contained in Saharan dust on the visits of children to the emergency department due to asthmatic conditions in Guadeloupe (French Archipelago of the Caribbean). PLoS One 9:e91136

7. Cai J, Zhao A, Zhao J, Chen R, Wang W, Ha S, Xu X, Kan H (2014) Acute effects of air pollution on asthma hospitalization in Shanghai, China. Environ Pollut Barking Essex 1987 191:139-144

8. Cakmak S, Dales RE, Coates F (2012) Does air pollution increase the effect of aeroallergens on hospitalization for asthma? J Allergy Clin Immunol 129:228-231

9. Caserio-Schonemann C, Meynard JB (2015) Ten years experience of syndromic surveillance for civil and military public health, France, 2004-2014. Euro Surveill Bull Eur Sur Mal Transm Eur Commun Dis Bull 20:35-38

10. Dab W, Ségala C, Dor F, Festy B, Lameloise P, Le Moullec Y, Le Tertre A, Medina S, Quénel P, Wallaert B et al (2001) Pollution Atmosphérique et Santé: Corrélation ou Causalité? Le Cas de la Relation entre l'Exposition aux Particules et la Mortalité Cardiopulmonaire. J Air Waste Manag Assoc 51:203-219

11. Dick S, Friend A, Dynes K, Alkandari F, Doust E, Cowie H, Ayres JG, Turner SW (2014) A systematic review of associations between environmental exposures and development of asthma in children aged up to 9 years. BMJ Open 4:e06554

12. Evans KA, Halterman JS, Hopke PK, Fagnano M, Rich DQ (2014) Increased ultrafine particles and carbon monoxide concentrations are associated with asthma exacerbation among urban children. Environ Res 129:11-19
13. Focal 81 internet.indd - focal81.pdf 2016. Available online: http:// www.insee.fr/fr/insee regions/limousin/themes/focal/focal-81/ focal81.pdf Accessed 201622 Dec

14. Gleason JA, Bielory L, Fagliano JA (2014) Associations between ozone, PM2.5, and four pollen types on emergency department pediatric asthma events during the warm season in New Jersey: a case-crossover study. Environ Res 132:421-429

15. Goeminne PC, Kiciński M, Vermeulen F, Fierens F, De Boeck K, Nemery B, Nawrot TS, Dupont LJ (2013) Impact of air pollution on cystic fibrosis pulmonary exacerbations: a case-crossover analysis. Chest. avr 143:946-954

16. Goldizen FC, Sly PD, Knibbs LD. 2015. Respiratory effects of air pollution on children. Pediatr Pulmonol 2015 (Epub ahead online)

17. Guarnieri M, Balmes JR (2014) Outdoor air pollution and asthma. Lancet 383:1581-1592

18. Just J (2011) Impact of pollution on asthma in young infants. Rev Fr Allergol 51:144-147

19. Just J, Nisakinovic L, Laoudi Y, Grimfeld A (2006) Air pollution and asthma in children. Arch Pédiatr 13:1055-1060

20. Larrieu S, Rivière S, Lefranc A, Chardon B, Declercq C, Le Tertre A, Borelli D, Blanchard M, Fabre P, Jusot JF et al (2006) P2-6 Associations à court terme entre pollution atmosphérique urbaine et hospitalisations pour pathologies cardiovasculaires et respiratoires : résultats et applications du programme Psas-9. Rev d'Épidémiologie Santé Publique 54(Supplement 2):67

21. Lee S, Chiu SS, Malik PJ, Chan KH, Wong HS, Lau YL (2011) Is respiratory viral infection really an important trigger of asthma exacerbations in children? Eur J Pediatr 170:1317-1324

22. Pascal M, Corso M, Chanel O, Declercq C, Badaloni C, Cesaroni G, Henschel S, Meister K, Haluza D, Martin-Olmedo P et al (2013) Assessing the public health impacts of urban air pollution in 25 European cities: results of the Aphekom project. Sci Total Environ 449:390-400

23. Renzetti G, Silvestre G, D'Amario C, Bottini E, Gloria-Bottini F, Bottini N, Auais A, Perez MK, Piedimonte G (2009) Less air pollution leads to rapid reduction of airway inflammation and improved airway function in asthmatic children. Pediatrics 123:1051-1058

24. Saadeh R, Klaunig J (2014) Child's development and respiratory system toxicity. J Environ Anal Toxicol 4:1-8

25. Samoli E, Nastos PT, Paliatsos AG, Katsouyanni K, Priftis KN (2011) Acute effects of air pollution on pediatric asthma exacerbation: evidence of association and effect modification. Environ Res 111:418-424

26. Sun H-L, Chou M-C, Lue K-H (2006) The relationship of air pollution to $\mathrm{ED}$ visits for asthma differ between children and adults. Am J Emerg Med 24:709-713

27. Tosca MA, Ruffoni S, Canonica GW, Ciprandi G (2014) Asthma exacerbation in children: relationship among pollens, weather, and air pollution. Allergol Immunopathol 42:362-368

28. Tzivian L (2011) Outdoor air pollution and asthma in children. J Asthma 48:470-481

29. Wendt JK, Symanski E, Stock TH, Chan W, Du XL (2014) Association of short-term increases in ambient air pollution and timing of initial asthma diagnosis among medicaid-enrolled children in a metropolitan area. Environ Res 131:50-58

30. World Health Organization (WHO). 2014. Ambient (outdoor) air quality and health. Available online: http://www.who.int/ mediacentre/factsheets/fs313/en/ Accessed 201622 Dec

Clinical trial registration: "Commission Nationale Informatique et Libertés" (CNIL) (The French data protection authority): no. 1887366; Ethics committee of French Pediatrics Society: CER_SFP 2015-005 